DOI: http://dx.doi.org/10.20396/sss.v16i2.8651464

(cc) $\mathrm{BY}-\mathrm{NC}-\mathrm{SA}$

\title{
POĹtICA NACIONAL dE ATENÇÃO hOSPITALAR: IMPACTOS PARA O TRABALHO DO ASSISTENTE SOCIAL
}

\author{
NATIONAL POLICY OF HOSPITAL ATTENTION: IMPACTS TO THE \\ SOCIAL WORKER'S WORK
}

\author{
Laura Marcelino Leal ${ }^{1}$ \\ Marina Monteiro de Castro e Castro ${ }^{2}$
}

\section{RESUMO}

Este artigo tem por objetivo problematizar o cotidiano de trabalho do assistente social no âmbito hospitalar, tendo por base as indicações da Política Nacional de Atenção Hospitalar (PNHOSP) a partir de elementos como apoio matricial, clínica ampliada, gerenciamento de leitos, horizontalização do cuidado, linha de cuidado, prontuário único e visita aberta; e aspectos presentes no cotidiano profissional, como as condições de trabalho, o sigilo profissional e o registro no prontuário único. A metodologia utilizada teve como base a abordagem qualitativa e o método crítico-dialético. A pesquisa de campo foi realizada com assistentes sociais que atuam no setor hospitalar em Juiz de Fora/MG. As estratégias de qualidade e humanização em saúde são gestadas num contexto tanto de reestruturação produtiva quanto de "reforma gerencial do Estado. Os eixos assistenciais apontam para a implementação incisiva de uma lógica empresarial na saúde, evidenciando a disputa de projetos para o setor. Além de ser marcado pela centralidade médica e pela ênfase no campo biológico. Apesar das dificuldades, há um esforço dos profissionais em atuarem em consonância com o Projeto ÉticoPolítico e o Código de Ética profissional.

\footnotetext{
${ }^{1}$ Assistente Social. Residente de Serviço Social do Programa de Residência Multiprofissional em Saúde do Adulto do Hospital Universitário da Universidade Federal de Juiz de Fora. Membro do Grupo de Estudos e Pesquisa em Fundamentos do Serviço Social, GEPFSS/UFJF. E-mail: lauraleal53@ yahoo.com.br. Telefone: (32) 988578299.

2 Assistente social. Doutora em Serviço Social (ESS/UFRJ). Professora da Faculdade de Serviço Social da Universidade Federal de Juiz de Fora. Membro do Grupo de Estudos e Pesquisa em Fundamentos do Serviço Social - GEPFSS/UFJF. E-mail: marinamccastro@yahoo.com.br.
} 
PALAVRAS-CHAVE: Hospital. Humanização. Serviço Social.

\section{ABSTRACT}

This article aims to problematize the daily work of the social worker in the hospital, based on the National Policy of Hospital Attention (PNHOSP) from elements such as matrix support, extended clinic, bed management, horizontalization care, care line, unique medical records and an open visit, and aspects present in the daily routine, such as working conditions, professional secrecy and registration in the single medical record. It was used a qualitative approach and a dialectical critical methodology. The survey has been done with Social workers in hospitals of Juiz de Fora Municipality. The strategies of quality and humanization in health are born in a context of both productive restructuring and "state management reform. The assistance axes point to the incisive implementation of a business logic in health, evidencing the dispute of projects for the sector. In addition to being marked by medical centrality and the emphasis on the biological field. Despite the difficulties, there is an effort of the professionals to act in consonance with the Ethical-Political Project and the Professional Code of Ethics.

KEYWORDS: Hospital. Humanization of work. Social Work.

\section{INTRODUÇÃO}

A Política Nacional de Atenção Hospitalar (PNHOSP) foi criada pela portaria $n^{\circ}$ 3.390 de dezembro de 2013, com o objetivo de estabelecer diretrizes para a organização do componente hospitalar da Rede de Atenção à Saúde (RAS), tendo por base a Política Nacional de Humanização. As suas disposições passam a ser referência para todos os hospitais, sejam públicos ou privados, que prestam ações e serviços no âmbito do Sistema Único de Saúde (SUS).

Os eixos estruturantes da PNHOSP são a assistência e gestão hospitalar, formação, desenvolvimento e gestão da força de trabalho, financiamento e contratualização, além das responsabilidades das esferas de gestão.

A atenção hospitalar, como um ponto central da RAS, vem sendo construída a partir de elementos normativos que confluem para a consolidação de uma rede articulada de serviços de saúde. No entanto, ao mesmo tempo, se alinha a uma concepção gerencialista (SANTOS E PINTO, 2017); se desenvolve através de um subfinanciamento que impacta diretamente na resolutividade dos cuidados ofertados pelos hospitais (HOLZ et al, 2016); e acompanha as proposições do Banco Mundial para a política de saúde brasileira a partir das 
estratégias postas pelo "Programa de Formação e Melhoria da Qualidade das Redes de Atenção à Saúde (RAS) - QualiSUS Redes" (CASTRO, 2016).

Neste artigo, problematizaremos o cotidiano de trabalho do assistente social no âmbito hospitalar, tendo por base as indicações da PNHOSP no âmbito da assistência, isto é, das ações voltadas para o atendimento direto às necessidades dos usuários que devem ser baseadas em equipe multiprofissional, horizontalização e organização de linhas de cuidado, e na regulação do acesso.

Os apontamentos que vem sendo preconizados pela política através do Ministério da Saúde (MS) foram trabalhados a partir de elementos críticos em torno da contrarreforma do Estado e da política de saúde, haja vista que o trabalho do assistente social sofre impactos diretos deste processo.

Esta análise se torna necessária em meio às demandas cada vez mais complexas, fruto do processo de agudização das expressões da questão social, que acabam por exigir respostas imediatas do assistente social. Assim, se faz necessário uma análise crítica da realidade para que os profissionais não reproduzam meramente uma lógica ministerial.

\section{MÉTODO}

O presente artigo é fruto da pesquisa realizada entre os anos de 2016/2017 com o título "O cotidiano de trabalho do assistente social: reflexões sobre o setor hospitalar em Juiz de Fora", submetida ao Comitê de Ética da Universidade Federal de Juiz de Fora (UFJF) e aprovada sob parecer de número 1.821.500.

O estudo considerou como critério de inclusão assistentes sociais que atuam na Atenção Terciária em Juiz de Fora, e como critério de exclusão as instituições que não são campo de estágio da Faculdade de Serviço Social/UFJF, tendo em vista que os profissionais supervisores possuem contato constante com o processo formativo, seja por meio do estágio ou pela preceptoria da residência contemplando, assim, eixos que são destacados nos Parâmetros para atuação do assistente social na Política de Saúde (CFESS, 2010), como centrais para o desenvolvimento do trabalho profissional. 
Cabe destacar ainda que não foram incluídos assistentes sociais supervisores de estágio que estivessem em hospitais, mas atuando em setor ambulatorial. Uma vez que a proposta é analisar a assistência hospitalar no âmbito da internação.

No que tange ao cenário de estudo, percebemos distintas naturezas com relação às instituições, sendo pública, privada e convênio com o SUS. Além disso, cabe ressaltar que estes hospitais são referências regionais, tendo em vista o porte da cidade e também a localização geográfica, uma vez que há muitos municípios de pequeno porte que são referenciados em Juiz de Fora. Neste sentido, cabe destacar que estas instituições hospitalares prestam tanto serviços de atendimentos gerais quanto de atendimentos especializados.

\section{RESULTADOS}

\section{A Política de Atenção Hospitalar no Brasil}

O debate em torno da assistência hospitalar ganha destaque ao final dos anos 1990 por meio da construção de um Programa Nacional de Humanização com foco neste nível de atenção. Àquele momento, o diagnóstico era de que a situação dos hospitais brasileiros estava vinculada ao sucateamento do setor, com um número significativo de queixas dos usuários sobre o serviço, e também por parte dos trabalhadores em saúde, além de aspectos relacionados à infraestrutura. Diante deste cenário, é colocada pelo Ministério da Saúde a necessidade de se desenvolver um conjunto de ações integradas na assistência hospitalar, de modo a avançar na qualidade do atendimento no âmbito do SUS (CASTRO, 2015).

Assim, foram estabelecidas propostas no campo da humanização hospitalar nos anos 2000, através do Programa Nacional de Humanização da Atenção Hospitalar (PNHAH). No entanto, estas foram dispostas de forma focalizada e segmentada por área (idoso, mulher) e níveis de atenção, recortando e restringindo a saúde (BENEVIDES E PASSOS, 2005).

Com a perspectiva de avançar no debate da humanização em saúde, no ano de 2003, foi disposta a Política Nacional de Humanização (PNH). Dentre os principais eixos e temáticas destaca-se o cuidado em saúde, gestão participativa e cogestão, valorização do trabalhador, ambiência, trabalho em equipe, defesa dos direitos dos usuários, redes e protagonismos, corresponsabilidades e autonomia dos sujeitos. 
Ao analisarmos atentamente os eixos e conteúdos da $\mathrm{PNH}$, verificamos que há um apelo a tônica do autocuidado, isto é, de atribuir aos usuários o cuidado com sua saúde, desprezando os fatores sociais que incidem no processo saúde-doença, além de responsabilizar os trabalhadores pela "qualidade" do trabalho. O que se visualiza é um fortalecimento da perspectiva gerencial, com foco na eficiência e na qualidade, por viés mercadológico.

A discussão da humanização obtém contornos aparentemente democráticos, ao perpassar os aspectos da qualidade do serviço prestado ao usuário. Porém, não retoma de forma consistente a concepção de Reforma Sanitária e dos princípios do SUS. Assim, a proposta se coaduna mais diretamente ao contexto da contrarreforma do Estado (CASTRO, 2015).

A PNH concretiza a perspectiva de flexibilizar o "projeto de reforma sanitária construído nos anos 1980, incorporando um conceito de saúde que "camufla" as reais condições de vida, trabalho e saúde dos usuários e trabalhadores e contribui para a mercadorização da saúde" (CASTRO, 2015, p.145).

Tem-se neste cenário, uma lógica ainda mais quantitativa, isto é, aumentam-se os níveis de exigência de desempenho aliado à exploração da força de trabalho. No bojo deste processo, podemos citar como exemplo o Programa de Acreditação Hospitalar criado em 2001.

Cabe destacar que as estratégias de qualidade e humanização em saúde são gestadas num contexto tanto de reestruturação produtiva quanto de "reforma gerencial do Estado", onde o hospital obtém centralidade enquanto eixo norteador das ações e serviços em saúde. No entanto, este nível de atenção mantém-se centrado na doença, além de se constituir enquanto um lócus privilegiado de ações que envolvem grande volume de capitais, tecnologias e equipamentos, fomentando uma lógica mercadológica e privatista.

O debate em torno dos hospitais ganha ainda mais destaque com a elaboração do “Caderno HumanizaSUS - Atenção Hospitalar” (BRASIL, 2013). Dentre os eixos trazidos neste, destacamos: atenção hospitalar em rede; dimensão de planificação na Política de Humanização na Atenção e Gestão em Saúde; pistas metodológicas para se avançar na humanização dos hospitais; clínica ampliada e acolhimento: desafios e articulações em construção para a humanização hospitalar; visita aberta e direito a acompanhante: garantia de acesso, de inclusão e de cidadania.

Serv. Soc. \& Saúde, Campinas, SP v.16, n. 2 (24), p. 211-228, jul./dez. 2017 E-ISSN 2446-5992 
Mesmo que os hospitais apresentem especificidades nos serviços de saúde por sua alta tecnologia, os Cadernos (BRASIL, 2013, p.13) enfatizam que "não constituem ilhas por excelência, à parte da rede de serviços”. Neste sentido, é fundamental que os parâmetros adotados considerem os hospitais em sua inserção na RAS.

A construção da Política Nacional de Atenção Hospitalar através da Portaria n ${ }^{\circ} 3.390$, no ano de 2013, veio no sentido de estabelecer diretrizes para organização do componente hospitalar da RAS.

O debate em torno da elaboração do documento da Política começou em 2012, desencadeado tanto pelo Ministério da Saúde quanto pelo Conselho Nacional de Secretários de Saúde (CONASS). Neste processo, foi destacada a portaria ${ }^{\circ} 4279$, de 30/12/2010 que estabelece a RAS no âmbito do SUS e elenca como principais desafios: "lacunas assistenciais importantes"; "financiamento público insuficiente, fragmentado e baixa eficiência no emprego dos recursos, com redução da capacidade do sistema de prover integralidade da atenção à saúde"; "configuração inadequada de modelos de atenção"; "fragilidade na gestão do trabalho com grave problema de precarização e carência de profissionais"; e a “pulverização dos serviços nos municípios”.

Assim, as diretrizes preconizadas pela PNHOSP perpassam pela defesa da garantia da universalidade de acesso, equidade e integralidade, bem como da centralidade de um modelo de atenção centrado no cuidado do usuário, além do financiamento pactuado com as três esferas de gestão.

$\mathrm{O}$ artigo $5^{\circ}$ da PNHOSP traz alguns apontamentos fundamentais no que tange a organização e funcionamento da instituição hospitalar. Dentre elas, destacamos aquelas relacionadas à assistência: apoio matricial, clínica ampliada, gerenciamento de leitos, horizontalização do cuidado, linha de cuidado, prontuário único e visita aberta.

Como assinalado, a PNHOSP estabelece que suas medidas devam ser aplicadas a todos os hospitais que prestem ações e serviços de saúde no âmbito do SUS. Esta proposição se coloca enquanto um desafio ao retratarmos o hospital como uma estrutura organizacional tradicional, com relações desiguais e assimétricas (PIRES, 2008). Ao mesmo tempo, se coloca enquanto uma instituição complexa, com densidade tecnológica, com caráter multiprofissional e interdisciplinar, que deve articular suas ações com a Atenção Básica de Saúde e primar pela formação de recursos humanos.

Serv. Soc. \& Saúde, Campinas, SP v.16, n. 2 (24), p. 211-228, jul./dez. 2017 E-ISSN 2446-5992 
O desafio se amplia, pois esta proposição é tensionada pelo projeto privatista e pelo subfinanciamento da política de saúde que incide, muitas vezes, em uma gestão gerencial, verticalizada e pouco participativa.

Ademais, o Estado impulsiona a criação de organizações sociais (OSs), fundações públicas, Organização da Sociedade Civil de Interesse Público (OSCIPs) para executar a política de saúde. No âmbito hospitalar, em 2011 tivemos a criação da Empresa Brasileira de Serviços Hospitalares (EBSERH) - empresa pública de direito privado que passou a gerir os hospitais universitários no país. Analisamos este processo enquanto fruto de uma ofensiva do capital em precarizar as relações de trabalho, além de mercantilizar a política de saúde.

Nesta acepção, são fundamentais mudanças estruturais e também organizacionais, de modo a incluir no centro do modelo de atenção as reais necessidades da população. Este deverá ser o eixo norteador de qualquer proposta que almeje trazer qualidade à assistência hospitalar e a construção democrática das decisões.

\section{Atenção Hospitalar e o trabalho do assistente social}

A área da saúde é historicamente uma das grandes frentes de atuação profissional do assistente social. No entanto, Matos (2013) aponta que ainda há um descompasso entre o cotidiano profissional, o Projeto Ético Político e o Projeto de Reforma Sanitária. Para este autor há dois fatores que são relevantes nesta análise

$\mathrm{O}$ primeiro se refere à dificuldade de se efetivar, por parte dos governos de diferentes esferas, a política universal e de direitos que o SUS preconiza, bem como à forma como está estruturado o trabalho coletivo em saúde, que se configura por meio de várias ações profissionais fragmentadas, sobrepostas, com pouca ou nenhuma interdisciplinaridade, tendo como objeto de suas ações a doença e não a saúde propriamente dita. Esta problemática não atinge só o trabalho dos assistentes sociais, mas, sim, o coletivo dos trabalhadores da saúde. O outro fator refere-se à nebulosa concepção da própria categoria de assistentes sociais, e também dos outros trabalhadores da saúde, sobre qual a particularidade do seu exercício profissional no âmbito do SUS (MATOS, 2013, p. 62).

Nessa perspectiva, é essencial que o assistente social tenha clareza sobre as suas competências e atribuições profissionais. Na saúde, conforme os Parâmetros de atuação dos assistentes sociais na política de saúde (CFESS, 2010, p. 26) o objetivo do trabalho profissional "passa pela compreensão dos determinantes sociais, econômicos e culturais que Serv. Soc. \& Saúde, Campinas, SP v.16, n. 2 (24), p. 211-228, jul./dez. 2017 E-ISSN 2446-5992 
interferem sobre o processo saúde e doença e na busca de estratégias político-institucionais para o enfrentamento dessas questões".

É necessário também refletirmos sobre o impacto do processo da contrarreforma do Estado para a atuação do assistente social, tendo em vista a diminuição do investimento em políticas sociais e o aumento das desigualdades, que se manifesta em precárias condições de trabalho e de vida para a maioria da população brasileira.

No que tange ao trabalho no âmbito hospitalar, consideramos fundamental a discussão dos eixos assistenciais, tendo em vista que estes se colocam como uma dos principais frentes de atuação do assistente social no atendimento aos usuários dos serviços de saúde (CFESS, 2010).

Assim, na pesquisa realizada junto aos assistentes sociais que atuam no setor hospitalar em Juiz de Fora, levantamos as principais questões que atravessam o cotidiano profissional na assistência hospitalar a partir de eixos preconizados pela PNHOSP: apoio matricial, horizontalização e linhas de cuidado, gerenciamento de leito, visita aos pacientes internados.

\section{Eixos assistenciais da PNHOSP e as implicações para o trabalho profissional}

O apoio matricial é compreendido pela PNHOSP (2013) como o suporte técnico especializado que é ofertado a uma equipe interdisciplinar de saúde a fim de ampliar seu campo de atuação e qualificar suas ações, invertendo a lógica de fragmentação dos saberes. Estimula o trabalho em equipe, visando uma atenção mais integral do usuário.

Esta proposta pauta-se nas estratégias destacadas pela PNH de transformação da estrutura das ações assistenciais, através da constituição da clínica ampliada, formação de projetos terapêuticos e equipes de referência para a realização de ações em saúde comprometidas com a realidade dos usuários.

Todavia, a pesquisa evidenciou que o apoio matricial apresenta diversas dificuldades de operacionalização no cotidiano do exercício profissional devido à centralidade médica, a visão hospitalocêntrica e o foco na doença.

Um dos maiores desafios do apoio matricial se encontra no fato de não haver espaços efetivos onde a equipe possa acompanhar conjuntamente os usuários e debater sobre o seu plano de cuidado.

Serv. Soc. \& Saúde, Campinas, SP v.16, n. 2 (24), p. 211-228, jul./dez. 2017 E-ISSN 2446-5992 
Segundo Silva e Santos (2006) apenas um trabalho de real integração e o estabelecimento de interrelações entre as diversas profissões, propiciará a criação de condições para se enfrentar a complexidade do cuidar a partir da integralidade. Desta forma, ressalta-se o apontamento de Peduzzi (2001, p.105-106) de que a equipe pode funcionar como agrupamento de agentes ou como integração de trabalho. "A primeira é caracterizada pela fragmentação e a segunda pela articulação consoante à proposta de integralidade das ações de saúde".

Diante dos dados da pesquisa, observamos que o trabalho em equipe não se apresenta de forma articulada, e se constitui enquanto um agrupamento de agentes, conforme Peduzzi (2001). Uma das assistentes sociais apontou que não há na instituição em que atua, nenhum movimento para um trabalho articulado entre a equipe:

Eu vejo isso como um grande vácuo. Já falei que o Serviço Social é muito reconhecido e tudo mais. Mas a gente não tem essa integração, o trabalho em equipe. Cada um no seu quadrado. O espaço que a gente tem de integração é o prontuário, mas é um computador, não é uma relação (LEAL, 2017, p. 85).

Dessa forma, “é necessário desmistificar a ideia de que a equipe, ao desenvolver ações coordenadas, cria uma identidade entre os seus participantes que leva à diluição de suas particularidades profissionais" (IAMAMOTO, 2002, p. 41). Ao contrário desta ideia, o trabalho em equipe exige que os profissionais tenham ainda mais clareza de suas atribuições, e que cada profissional possa contribuir dentro das suas especificidades para o tratamento dos usuários.

Agregado a este processo, tem-se a natureza do espaço hospitalar, fortemente marcado por modelos verticalizados, focados na doença e no tratamento, permeado por pactuações para o desenvolvimento do trabalho que colocam os médicos em posição privilegiada, com baixa interlocução com outras áreas. Nas palavras de Cecílio (1999, p. 317), "no tradicional modo de se fazer a gestão em hospitais, os médicos gozam de alto grau de autonomia, não estando submetidos a praticamente nenhum mecanismo de controle. Os médicos têm muito poder nas organizações".

Cecílio (1999) assinala que a categoria médica evita qualquer tipo de ações que submeta o seu trabalho ao de outros profissionais, bem como da parte burocrática do exercício profissional. Essa tese discutida pelo autor foi identificada na pesquisa, Serv. Soc. \& Saúde, Campinas, SP v.16, n. 2 (24), p. 211-228, jul./dez. 2017 E-ISSN 2446-5992 
principalmente no que se refere ao preenchimento de laudos, relatórios e atestados médicos, onde parcela dos profissionais assume postura que, muitas vezes, dificulta o acesso dos usuários aos seus direitos.

Destacamos que a responsabilidade dos médicos na oferta de atestados é regulamentada pela Resolução do Conselho Federal de Medicina (CFM) número n. ${ }^{\circ}$ $1.658 / 2002$ - que foi em parte alterada pela Resolução CFM no 1.851/2008. Conforme CFM (2002, p.1) "o atestado médico é parte integrante do ato médico, sendo seu fornecimento direito inalienável do paciente".

Desta forma, ao dificultar os trâmites de elaboração do documento, o profissional pode impedir o acesso do usuário a um direito que poderia ser decisivo nas suas condições objetivas para enfrentamento do processo saúde-doença. Além de uma visão restrita da saúde, tal postura expressa uma visão de "cuidar" que se pauta na intervenção sobre um objeto - a doença.

Curar, tratar, controlar tornam-se posturas limitadas. Todas essas práticas supõem, no fundo, uma relação estática, individualizada e individualizante, objetificadora, enfim, dos sujeitos alvo de nossas intervenções.[...] Por isso, cuidar, no sentido de um "tratar que seja", que passa pelas competências e tarefas técnicas, mas não se restringe a elas, encarna mais ricamente que tratar, curar ou controlar aquilo que deve ser a tarefa prática da saúde coletiva (AYRES, 2001, p.70-71).

Outra questão que envolve o trabalho do assistente social em articulação com a equipe, se relaciona as demandas indevidas encaminhadas para o profissional. Como pode ser visto:

O paciente está brigando com a esposa dele, chamam o assistente social para ver o que é. Essa questão que é muito particular do paciente, eles ainda acham que o Serviço Social tem a aquela formação policialesca. [...] É como se o Serviço Social tivesse que colocar as pessoas no padrão da ética e dos bons costumes (LEAL, 2017, p. 88).

Nesse sentido, é fundamental discutirmos o cotidiano haja vista que o conservadorismo da gênese da profissão ainda permeia o imaginário social em relação o papel do Serviço Social. Uma estratégia relatada durante a pesquisa para clarificar junto à equipe a atuação do assistente social, foi a criação de um folder lúdico pelo setor de Serviço Social sobre o que é profissão, as suas atribuições, principais demandas e, também, o que não compete aos assistentes sociais.

Serv. Soc. \& Saúde, Campinas, SP v.16, n. 2 (24), p. 211-228, jul./dez. 2017 E-ISSN 2446-5992 
Refletir sobre o apoio matricial e o trabalho em equipe no cenário hospitalar requer pensarmos nas ações voltadas aos usuários e suas necessidades, e não exclusivamente nas categorias profissionais. Tomar essa prática requer mudanças estruturais nas organizações dos serviços de saúde:

O conceito "trabalho em equipe" é uma preocupação antiga, na medida em que nenhum profissional consegue, isoladamente, alcançar a finalidade do trabalho em saúde. Mas é flagrante, a ausência de sistematização, o que prejudica os trabalhos de melhor qualidade em saúde. $\mathrm{Na}$ formação acadêmica, em geral, os profissionais recebem apenas o conhecimento estrito dos conteúdos disciplinares, sem elo de mediação objetiva (STEPHAN-SOUZA; MOURÃO, 2001-2002, p. 35).

No que tange a horizontalização do cuidado e as linhas de cuidado, estas são destacadas na PNHOSP como:

[...] horizontalização do cuidado: a forma de organização do trabalho em saúde, na qual existe uma equipe multiprofissional de referência que atua diariamente no serviço, em contraposição à forma de organização do trabalho em que profissionais têm uma carga horária distribuída por plantão; linha de cuidado: a estratégia de organização da atenção que viabiliza a integralidade da assistência, por meio de um conjunto de saberes, tecnologias e recursos necessários ao enfrentamento de riscos, agravos ou demais condições específicas do ciclo de vida ou outro critério sanitário a serem ofertados de forma oportuna, articulada e contínua, abrangendo os campos de promoção prevenção, tratamento e reabilitação (BRASIL, 2013, p. 3).

Na pesquisa, foi identificado que há uma tentativa das instituições em organizarem o trabalho em linhas de cuidados, mas este ocorre em apenas alguns setores do hospital. Os usuários que estão internados nestes setores são priorizados para o atendimento do Serviço Social.

O que se destaca nesta organização é a centralidade médica na condução das atividades e das reuniões de equipe. Nesse sentido, foram apontados aspectos como: a centralidade médica nas decisões com relação ao paciente, em detrimento da equipe; a segregação do espaço físico, a visão fragmentada dos usuários, além de questões como a falta de isonomia salarial.

Em uma Instituição, as equipes das linhas de cuidado são coordenadas por médicos, que recebem gratificações para estar nesta equipe, o que não ocorre com as outras categorias profissionais. Foi relatada também a questão da hegemonia médica na relação com os demais membros da equipe e com os próprios usuários. 
Um exemplo: doutor, o paciente precisa de um equipamento em casa, e o equipamento vai chegar amanhã, o senhor pode dar essa alta amanhã? Não, vou dar hoje. Então, o médico é sempre a última palavra. Eles não entenderam que liberar um paciente e não ver as determinações sociais, só vai fazer o paciente ir para casa e voltar. O médico não consegue enxergar a totalidade (LEAL, 2017, p. 90).

No que concerne ao gerenciamento de leito, este é posto pela PNHOSP (2013, p.3) como um "dispositivo para a otimização da utilização dos leitos, aumentado a rotatividade dentro dos critérios técnicos, visando diminuir o tempo de internação desnecessário a abrir novas vagas para as demandas represadas".

A pesquisa realizada demonstrou que este eixo é atravessado por questões que envolvem a internação social, ou seja, período em que o usuário já teve alta médica, mas não possui condições de retornar para um local que possibilite a continuidade do seu tratamento ou recuperação pós-alta. Neste sentido, o Serviço Social vivencia pressões para uma liberação ágil do leito que, muitas vezes, não coincide com as possibilidades de serviços dispostos na rede sócio-assistencial e de saúde e com as condições objetivas e subjetivas da família ou da rede de solidariedade para acolhimento do usuário.

Internação social é uma dificuldade, todo dia: o Serviço Social já deu um posicionamento? A internação clínica ninguém discute. Agora internação social é problema. A gente tem que ficar evoluindo quase que de 5 em 5 minutos falando o porquê aquele paciente não está de alta. Isso quando a gente consegue a internação social. Passou para alta social é cobrança por causa do leito (LEAL, 2017, p. 93).

O gerenciamento de leito envolve ainda a judicialização da saúde. Quando há impedimento junto à rede de serviços ou família para acolhimento do usuário, é necessário a judicialização com vistas a garantir o direito ao tratamento de saúde, como destacado: "eu fiz contato com a Promotoria, o município alega que não tem condições para aquilo que precisa ser feito, você entra com recurso contra o Estado que alega que não tem condições de fazer. Aí os pacientes vão ficando" (LEAL, 2017, p. 93).

Sinalizamos que este aspecto revela o quanto as respostas às expressões da questão social têm sido negligenciadas por parte do Estado, fazendo com que os sujeitos acionem cada vez mais o judiciário, de modo a garantir algo que já é institucionalizado com um direito, que é o acesso à saúde. 
Outra questão é a reinternação dos usuários, tendo em vista o deferimento da alta sem as condições para efetivação da recuperação e do tratamento. Ou seja, a exigência pela rotatividade do leito acaba gerando uma nova demanda de internação.

No que diz respeito à visita aos usuários internados a PNHOSP (2013, p.3) estabelece a visita aberta através do "acesso de visitantes às unidades de internação em qualquer tempo, desde que negociado previamente entre usuário, profissionais, gestores e visitantes, de forma a garantir o elo entre o usuário e sua rede social de apoio".

Peres e Lopes (2012) discutem a importância da família para o tratamento do paciente:

A inclusão da família no processo de cuidado do paciente depende não só da forma como a instituição concebe ações de acompanhamento para a família. Depende também da maneira como a gestão do serviço de saúde integra a família dentro da organização dos processos de trabalho, e de como equipe e família se relacionam no acompanhamento e cuidado do paciente internado, cuidado este que deve abranger a dimensão psicossocial (PERES; LOPES, 2012, p. 21).

Compreendemos que esse posicionamento afirmado pela política como benéfico aos usuários, seus familiares e a rede de apoio social. No entanto, a pesquisa evidenciou que esta proposta ainda está longe de se efetivar na realidade dos serviços de saúde, sendo a visita estabelecida conforme a rotina do hospital. Diante disso, chegam diversas demandas para o Serviço Social mediar, principalmente para autorização de visitas fora do horário estabelecido pela Instituição.

\section{Condições de trabalho, ética e sigilo profissional}

Além dos eixos assistenciais dispostos pela PNHOSP (2013), abordamos na pesquisa elementos acerca das condições de trabalho, do sigilo profissional e do registro no prontuário único.

O debate das condições éticas e técnicas de trabalho foram baseados na resolução $\mathrm{n}^{\circ}$ 493 de 2006 do CFESS, que destaca aspectos como: iluminação adequada, recursos que garantam a privacidade, ventilação, e espaço adequado para a colocação de arquivos/ material técnico. 
De maneira geral, a estrutura física foi considerada um limite significativo para o desenvolvimento do trabalho, na medida em que repercute diretamente na qualidade do atendimento prestado ao usuário. Além disso, surgiram questões referentes à insuficiência de equipamentos como impressora e computador, e a falta de espaço físico para arquivamento do material técnico.

No âmbito hospitalar, uma das principais questões que atravessa o trabalho profissional se refere ao sigilo, tendo em vista não haver uma sala de atendimento nas enfermarias dos hospitais. Assim, os profissionais necessitam realizar a abordagem social no leito do usuário. Neste sentido, é colocado como questão "como realizar atendimento em um espaço com tantos pacientes e acompanhantes, além de outros profissionais?" A resposta a este questionamento não é simples, pois exige mudanças organizacionais e estruturais, além de discussões efetivas sobre o sigilo e a ética profissional (LEAL, 2017).

Com relação ao formato do prontuário, identificamos que há uma variação nas modalidades eletrônico e de papel. De acordo com Vasconcelos et. al. (2008), o prontuário é

Tratado aqui como registro em saúde, prontuário é definido como documento único, constituído de um conjunto de informações, sinais e imagens registradas, geradas com base em fatos, acontecimentos e situações sobre a saúde do paciente e a assistência a ele prestada, de caráter legal, sigiloso e científico, que possibilita a comunicação entre membros da equipe multiprofissional e a continuidade da assistência prestada ao indivíduo (VASCONCELOS et al, 2008, p. 173-174).

De acordo com Matos (2013, p. 111) "o prontuário surge como uma estratégia de sintetização das ações desenvolvidas pelos diferentes profissionais de saúde". Além disso, o autor coloca que este pode ser um elo de entendimento das diferentes dimensões que envolvem o processo saúde-doença enfrentado pelo usuário.

$\mathrm{Na}$ pesquisa, foi identificado que há uma preocupação com a forma de relato no prontuário único, com o objetivo de preservar o sigilo das informações trazidas pelos usuários. Além disso, os assistentes sociais possuem arquivo privativo, onde relatam questões apresentadas pelos usuários que não são pertinentes ao conjunto da equipe. 
De maneira geral notamos que, apesar das dificuldades, há um esforço dos profissionais em atuarem em consonância com o Projeto Ético- Político e o Código de Ética profissional:

A gente tem a possibilidade de fazer um trabalho diferente, de fornecer uma escuta qualificada com aquele usuário que às vezes não é escutado. Ser um profissional de referência para aquele usuário. Garantir o acesso aos serviços, programas, ou pelo menos tentar garantir, a potencialidade de levantar a bandeira da concepção ampliada de saúde, da defesa da saúde pública, dos princípios do SUS (LEAL, 2017, p. 98).

Nesta acepção, é fundamental um profissional capaz, de modo a compreender a realidade e, a partir disso, criar as mediações necessárias para se desenvolver um trabalho especializado. Iamomoto (2009) enfatiza que

O exercício da profissão exige um sujeito profissional que tenha competência para propor, para negociar com a instituição os seus projetos, para defender o seu campo de trabalho, suas qualificações e atribuições profissionais. Requer ir além das rotinas institucionais para buscar apreender, no movimento da realidade, as tendências e possibilidades, ali presentes, passíveis de serem apropriadas pelo profissional, desenvolvidas e transformadas em projetos de trabalho (IAMAMOTO, 2009, p. 12).

Tendo por base a discussão trazida neste artigo, vislumbramos um contexto adverso para as políticas sociais e, consequentemente, para o trabalho do assistente social. Mesmo assim, reiteramos o compromisso dos profissionais com uma saúde pública e de qualidade, vinculada a lógica do direito e da cidadania. Nesta direção, é fundamental o fomento dos espaços coletivos para enfrentar a ofensiva do capital, que tende a diminuir cada vez mais os direitos sociais e do trabalho; e evidenciar a necessidade de estarmos em reflexão permanente, tendo em vista as mudanças constantes na realidade, bem como a preservação da articulação entre teoria e prática profissional.

\section{CONSIDERAÇÕES FINAIS}

Discutir o cotidiano de trabalho é algo imprescindível de modo a visualizar os limites e as possibilidades de atuação e, a partir disso, buscar a construção de estratégias e mediações que possam qualificar ainda mais o trabalho do assistente social. Deste modo, ao questionar o cotidiano, o profissional potencializa as condições de estabelecer respostas mais elaboradas às demandas que chegam aos serviços de saúde.

Serv. Soc. \& Saúde, Campinas, SP v.16, n. 2 (24), p. 211-228, jul./dez. 2017 E-ISSN 2446-5992 
Fazer este exercício é indispensável, principalmente, em virtude das consequências da contrarreforma do Estado para o trabalho em saúde. Nesta direção, observamos três importantes elementos, o crescimento do setor de serviços privados, o aumento da terceirização na saúde e da "visão do cliente", isto é, a implementação incisiva de uma lógica empresarial na saúde. Aliado a estes fatores temos a hegemonia médica, o privilegiamento do modelo hospitalocêntrico e a disputa de projetos para a saúde.

Sobre este último eixo, compreendemos que o Estado deva ser o responsável por financiar e gerir os atendimentos em saúde. Ao mesmo tempo, percebemos que isso implica numa disputa aberta com o capital, na medida em que a este interessa o fomento do mercado, e não da ação pública direta do Estado.

Ao analisarmos as diretrizes recomendadas pelo MS, na maioria das vezes, estas contribuem para o discurso no nível micropolítico, porém, sem relacioná-lo ao macropolítico. Esta postura acaba por reforçar a seletividade das políticas sociais.

Ressaltamos, assim, que é fundamental o compromisso dos profissionais com uma saúde pública e com uma assistência de qualidade, vinculada a lógica do direito e da cidadania.

Recebido em 22.09.2017 - Aprovado em 26.12.2017

\section{REFERÊNCIAS}

AYRES, J. R. Sujeito, intersubjetividade e práticas de saúde. Revista Ciência e Saúde

Coletiva. Rio de Janeiro, v. 6, n. 1, p.63-72, 2001.

BENEVIDES, R.; PASSOS, E. Humanização na saúde: um novo modismo? Revista

Interface - Comunicação, Saúde, Educação, v. 9, mar./ago.2005.

BRASIL. Cadernos HumanizaSUS. Atenção Hospitalar. Disponível em:

http://bvsms.saude.gov.br/bvs/publicacoes/caderno_humanizasus_atencao_hospitalar.pdf.

Acesso em: 10 de junho de 2016. 
BRASIL. Nota técnica- Conselho Nacional de Saúde - CONASS. 2012. Disponível em: http://www.conass.org.br/biblioteca/wp-content/uploads/2013/01/NT-24-2013-PNOHOSPvf.pdf. Acesso em 14 de Junho de 2016.

BRASIL. Portaria no 3.390, de 30 de Dezembro de 2013. Disponível em: http://bvsms.saude.gov.br/bvs/saudelegis/gm/2013/prt3390_30_12_2013.html. Acesso em 15 de junho de 2016.

BRASIL. Programa Nacional de Humanização da Assistência Hospitalar. Disponível em: http://bvsms.saude.gov.br/bvs/publicacoes/pnhah01.pdf. Acesso em: 16 de Junho de 2016.

CASTRO, M. M. C. Humanização em Saúde: intencionalidade política e fundamentação teórica. Tese [Doutorado em Serviço Social]. UFRJ, ESS, 2015.

CASTRO, M. M. C. QualiSUS-redes e as proposições do Banco Mundial: problematizações críticas. REFACS (online). n. 4, v,2, p. 153-161.

CECÍLIO, L.C. Autonomia versus controle dos trabalhadores: a gestão do poder no hospital.

Revista Ciência e Saúde Coletiva. v. 4, nº 2, p. 315-329, 1999.

CFESS. Parâmetros para a Atuação de Assistentes Sociais na Política de Saúde. Série: trabalho e projeto profissional nas políticas sociais. Brasília, 2010.

CFESS. Resolução 493/2006. Disponível em:

http://www.cfess.org.br/arquivos/Resolucao_493-06.pdf. Acesso em: 10 de Setembro de 2016.

CFM. Resolução CFM n. ${ }^{0}$ 1.658/2002. Disponível em:

http://www.portalmedico.org.br/resolucoes/cfm/2002/1658_2002.htm. acesso em 19 de setembro de 2017.

CFM. Resolução CFM no 1.851/2008. Disponível em:

http://www.portalmedico.org.br/resolucoes/cfm/2008/1851_2008.htm. acesso em 19 de setembro de 2017.

HOLZ, C. B et al. O hospital na rede de atenção a saúde: uma reflexão teórica. Revista Espaço Ciência \& Saúde. v. 4, 2016, p. 101-115.

IAMAMOTO, M. Projeto Profissional, Espaços Ocupacionais e Trabalho do Assistente

Social na atualidade. Atribuições privativas do assistente social em questão: CFESS, 2002.

IAMAMOTO, M. O Serviço Social na cena contemporânea. CFEES/ABEPSS (Orgs).

Serviço Social: Direitos e Competências profissionais. Brasília, 2009.

Serv. Soc. \& Saúde, Campinas, SP v.16, n. 2 (24), p. 211-228, jul./dez. 2017 E-ISSN 2446-5992 
LEAL. L. O cotidiano de trabalho do assistente social: Reflexões sobre o setor hospitalar em Juiz de Fora. Trabalho de Conclusão de Curso/ Faculdade de Serviço Social/ Universidade Federal de Juiz de Fora, 2017.

MATOS, M. Serviço Social, ética e saúde: reflexões para o exercício profissional. - São Paulo: Cortez, 2013.

PEDUZZI, M. Equipe multiprofissional de saúde: conceito e tipologia. Revista Saúde Pública, vol.35, n.1, 2001, vol.35, n.1, p.103-109.

PIRES, D. Reestruturação produtiva e trabalho em saúde no Brasil. São Paulo: Confederação Nacional dos Trabalhadores em Seguridade Social, Annablume, 2008. SANTOS, T. B; PINTOS, I. C. M. Política Nacional de Atenção Hospitalar: con(di)vergências entre normas, Conferências e estratégias do Executivo Federal. Revista Saúde Debate. v. 41, n. especial 3, 2017, p. 99-113.

SILVA, L.B.; MENDES, A.G. Serviço Social, Saúde e a Interdisciplinaridade: algumas questões para o debate. SILVA, L. B; RAMOS, A. Serviço Social, Saúde e Questões Contemporâneas. São Paulo: Papel Social, 2013.

SILVA, L.M; SANTOS M.A. Construindo pontes: relato de experiência de uma equipe multiprofissional em transtornos alimentares. Medicina, Ribeirão Preto. Simpósio: transtornos alimentares: anorexia e bulimia nervosas. 2006, p. 415- 424.

STEPHAN-SOUZA, A.I; MOURÃO, A.M.A. A construção do trabalho em equipe: uma tarefa do coletivo dos profissionais de saúde. Revista de Atenção Primária. Juiz de Fora, ano IV, n 9, p.35-37, dez.2001/maio 2002.

VASCONCELOS, M. M.; GRIBEL, E. B.; MORAES, I. H. S. Registros em saúde: avaliação da qualidade do prontuário na Atenção Básica. Cadernos Saúde Pública. Rio de Janeiro, Fiocruz, n. 24 suplemento, 2008, p.173-182. 